\title{
Challenges Linked With Adherence to Treatment by Adult TB Patients in Pakistan
}

\author{
Fahmida Khatoon ${ }^{1}$, Atif Mahmood ${ }^{2}$, Mukkaram Ali $^{3}$, Saima Ejaz $^{4}$, Ghulam Ali $^{5}$ \\ ${ }^{I}$ Department of Biochemistry ${ }^{I}$, United Medical and Dental College, Karachi. \\ ${ }^{2}$ Department of Physiology ${ }^{2}$, Shaheed Mohtarma Benazir Bhutto Medical College, Lyari, Karachi. \\ ${ }^{3}$ Department of Forensic Medicine ${ }^{3}$, Dow International Medical College, Dow University of Health Sciences, \\ Karachi, Pakistan. \\ ${ }^{42}$ Department of Physiology, Dow International Medical College, Dow University of Health Sciences, Karachi, \\ Pakistan \\ ${ }^{5}$ Department of Forensic Medicine ${ }^{4}$, Sindh Medical College, Dow University of Health Sciences. Karachi, \\ Pakistan.
}

\begin{abstract}
To be aware of non compliant TB patients for drug loyalty and also investigating the dread for drugs in them. For public health community, tuberculosis (TB) has accessible confront in the developing countries although curative drugs exist, yet TB has remained the foremost killers among infectious diseases. The TB treatment regimen is long, intensive and fraught with potential side effects. For these reasons, only about 20\% of people with TB successfully complete treatment. Cross sectional survey was conducted on a non-probability purposive sample of 349 TB patients attending JPMC Chest OPD, Malir Chest Clinic and Ojha Institute of Chest Diseases, Karachi in the month of June and July, 2007. All the patients who were administered Antituberculous drugs (ATT) under Direct Observed Treatment Strategy (DOTS) in the above mentioned period were included in the study. The total response rate was 93\%. Out of 349 TB patients observed, 43\% [150] were males and 57\% [199] were females. $94 \%$ of the patients were following DOTS i.e. they regularly came to the clinics, but 5\% were those who did not follow it regularly and skipped the daily medicine. Only $13 \%$ have quit taking medication themselves. $60 \%$ of the patients experienced side effects of the anti-TB drugs whereas $40 \%$ didn't experience any side effects. Proper counseling regarding the treatment options and side effects of the treatment can help reduce the challenges associated with adherence to the TB treatment.
\end{abstract}

Keywords: DOTS therapy, Pakistan, Tuberculosis.

\section{Introduction:}

Tuberculosis (TB) is an infectious disease caused by Mycobacterium tuberculosis, and spreads by inhalation of infective droplets. Disease primarily affects lungs and impairs pulmonary functions but it can spread to almost any organ of the body. ${ }^{[1]} \mathrm{TB}$ is one of the 3 infectious diseases along with malaria and HIV that contributes to the major burden of communicable diseases. ${ }^{[2]}$ Each year nearly 9 million people emerge as new cases of TB of which about 2 million die predominantly in developing countries. ${ }^{[3]}$ Although TB is an ancient disease, it still contributes significantly to global human mortality and mortality. ${ }^{[4]}$

Despite the fact that the disease is preventable and curable; the development of effective treatment for $\mathrm{TB}$ continues to be a challenge all over the world. ${ }^{[5]}$ Following the same treatment strategy that was developed 50 years ago; TB patients have to take medication on daily basis for 6 to 8 months or more depending on the severity of disease. ${ }^{[6]}$ The primary symptoms of the disease disappear in approximately $2-3$ months which leads many patients to stop the treatment and non-compliance as interruption in taking the drugs prevents the complete cure and increases the risk of relapse and development of drug resistance. ${ }^{7]}$ Thus poor adherence to the medication remains the major contributor that leads to the deterioration of the disease.

DOT is the strategy recommended by World Health Organization (WHO) to avoid such interruption of treatment. It has not only contributed in improving the TB control but has also helped in better understanding of factors that prevent patients from completing the course of medication which is required in order to improve the outcome of treatment. ${ }^{[3]}$ Following are some of the factors identified:

1. Financial burdens of treatment [distance and fares of transportation] ${ }^{[4,7-11]}$

2. Side effects of drugs ${ }^{[6,12,13]}$

3. Family, community and household influences

a. Isolation of patient by family ${ }^{[7]}$

b. Loss of job ${ }^{8,14-16]}$

c. Difficulty in marriage ${ }^{[17]}$

4. Personal behavior

a. High dose of drugs 

b. Long duration of therapy ${ }^{[18,19]}$
c. Dosage before breakfast ${ }^{[20]}$

5. Believes and knowledge about treatment
a. Effectiveness of treatment
b. Others sources of treatment ${ }^{[21]}$
c. Drugs use during pregnancy and lactation by women.

\section{Field work strategy:}

\section{Methods And Material:}

A cross sectional study with a purposive non-probability sampling was conducted from June to July 2007 at Jinnah Postgraduate Medical Center (JPMC) Chest OPD, Malir Chest Clinic and Ojha Institute of Chest Diseases (OICD). All the patients who were administered Anti-tuberculous drugs (ATT) under Direct Observed Treatment Strategy (DOTS) in the above mentioned period at these clinics were included in the study. Nonaffordability of the treatment was one of the major reasons why these patients were coming to government hospitals as most of them belonged to lower and middle socio-economic class. The number of questionnaires administered were 375 . Response rate was $93 \%$.

\section{Inclusion criteria:}

(i) The patients that have been on anti-TB drugs for at least one month, (ii) The patients showing cardinal clinical features of pulmonary TB, such as chronic cough, haemoptysis, weight loss and night sweats and (iii) Patients with age ranging between 12 and 55 years.

\section{Exclusion criteria:}

(i) Children below the age of 12 years, (ii) Newly diagnosed patients.

\section{Research design:}

Structured questionnaire and individual interviews were used to obtain information from TB patients. The structured questionnaire and interview questions were developed by consulting pharmacology textbooks and research journals under supervision of GA. The questionnaires were administered to patients with the following sections; (a) Demographic and socio-economic characteristics such as age, occupation and education, approximate income of the house. (b) Drug information; such as anti-TB drugs counseling, side effects of antiTB drugs and the reasons why patients stopped taking anti-TB drugs.

\section{Ethics approval:}

Ethical approval and written permission was obtained from Director OICD; in charge OPD, JPMC and owner, Malir Chest Clinic to conduct the research before administering the questionnaires to the patients. The informed consent was obtained from each and every patient and confidentiality of the data was assured.

\section{Data Collection and Analysis:}

Individuals' interviews were conducted by the trained students under the supervision of FK and AM to record the perspective of patients. Analysis of the completed questionnaires was carried out using Statistical Package for the Social Sciences (SPSS 16.0). The data were analyzed using descriptive statistics which involved the use of frequency distribution and percentages.

\section{Results:}

Table 1: Demographic and socio economic characteristics of TB patients

\begin{tabular}{|c|c|c|c|c|c|c|c|c|}
\hline \multirow{2}{*}{ Parameters Studied } & \multirow{2}{*}{ Classification } & \multicolumn{2}{|c|}{ Males } & \multicolumn{2}{|c|}{ Females } & \multicolumn{2}{|c|}{ Total } & \multirow{2}{*}{$p$ value $\square$} \\
\hline & & $(\mathbf{n})^{*}$ & $(\%)$ & (n) & $(\%)$ & (n) & $(\%)$ & \\
\hline \multirow{4}{*}{ Age in years } & $12-17$ & 8 & 5.3 & 36 & 18.1 & 44 & 12.6 & \multirow{4}{*}{$<0.001$} \\
\hline & $18-30$ & 45 & 30.0 & 79 & 39.7 & 124 & 35.5 & \\
\hline & $31-45$ & 47 & 31.3 & 63 & 31.6 & 110 & 31.5 & \\
\hline & 46 and above & 50 & 33.3 & 21 & 10.5 & 71 & 20.3 & \\
\hline \multirow{4}{*}{ Marital Status } & Single & 25 & 16.7 & 13 & 6.5 & 38 & 10.9 & \multirow{4}{*}{$<0.001$} \\
\hline & Married & 111 & 74.0 & 151 & 75.9 & 262 & 75.1 & \\
\hline & Widowed & 6 & 4.0 & 18 & 9.0 & 24 & 6.9 & \\
\hline & Divorced & 8 & 5.3 & 17 & 8.5 & 25 & 7.1 & \\
\hline \multirow{4}{*}{ Occupation } & Students/No employment & 24 & 16.0 & 71 & 35.7 & 95 & 27.2 & \multirow{4}{*}{$<0.001$} \\
\hline & Professionals & 21 & 14.0 & 9 & 4.5 & 30 & 8.6 & \\
\hline & Government Employees & 41 & 27.3 & 34 & 17.1 & 75 & 21.5 & \\
\hline & Businessmen & 31 & 20.6 & 13 & 6.5 & 44 & 12.6 & \\
\hline
\end{tabular}




\begin{tabular}{|c|c|c|c|c|c|c|c|c|}
\hline & Self employed & 33 & 22.0 & 72 & 36.2 & 105 & 30.1 & \\
\hline \multirow{4}{*}{ Education } & No formal education & 26 & 17.3 & 89 & 44.7 & 115 & 33.0 & \multirow{4}{*}{$<0.001$} \\
\hline & Primary school & 67 & 44.7 & 77 & 38.7 & 144 & 41.3 & \\
\hline & Secondary school & 46 & 30.7 & 29 & 14.6 & 75 & 21.5 & \\
\hline & Graduate or higher & 11 & 7.3 & 4 & 2.0 & 15 & 4.2 & \\
\hline \multirow{5}{*}{$\begin{array}{l}\text { Income of the } \\
\text { household p.m. }\end{array}$} & $<5000$ & 42 & 28.0 & 99 & 49.7 & 141 & 40.4 & \multirow{5}{*}{$<0.001$} \\
\hline & $5000-10000$ & 78 & 52.0 & 49 & 24.6 & 127 & 36.4 & \\
\hline & $10001-15000$ & 19 & 12.7 & 9 & 4.5 & 28 & 8.0 & \\
\hline & $>15000$ & 6 & 4.0 & 5 & 2.5 & 11 & 3.1 & \\
\hline & Not sure & 5 & 3.3 & 37 & 18.6 & 42 & 12.0 & \\
\hline \multirow{4}{*}{$\begin{array}{l}\text { Number of } \\
\text { dependants }\end{array}$} & None & 6 & 4.0 & 4 & 2.0 & 10 & 2.9 & \multirow{4}{*}{0.062} \\
\hline & $1-5$ & 57 & 38.0 & 72 & 36.2 & 129 & 36.9 & \\
\hline & $6-10$ & 68 & 45.4 & 111 & 55.8 & 179 & 51.3 & \\
\hline & $>10$ & 19 & 12.6 & 12 & 6.0 & 31 & 8.9 & \\
\hline
\end{tabular}

${ }_{\mathrm{n}}^{*}=$ Frequency, $\%=$ Percentage, $\neq p$ value $<0.05=$ significant, $<0.01=$ very significant, $<0.001=$ highly significant

Out of total 349 TB patients observed, 43\% (150) are males and 57\% (199) are females. Approximately half of the patients $(48.1 \%, \mathrm{n}=168)$ were less than 30 years of age. Majority of the patients included in the study were married $(75.1 \%, \mathrm{n}=262)$. Approximately $7 \%$ (24) patients were widowed out of these spouse of $58.4 \%$ $(n=14)$ had diagnosed TB before death. Majority of the females $(35.7 \%, n=71)$ were either students or not employed whereas $27.3 \%(n=41)$ of the males were government employees with jobs ranging from peon to clerks or office assistants.

Approximately $30.1 \%(n=105)$ patients were self employed and were either working as laborers on daily wages or were house servants. Most of the patients $(74.3 \%, n=159)$ either did not had any formal education or had formal education up to primary only. Majority of the patients $(76.8 \%, \mathrm{n}=168)$ attending these government hospitals belong to the class where the average income was up to Rs. 10000 per month only. The approximate income of a household was calculated to be Rs. 6874 only. According to data, the income of $28 \%$ males $(n=42)$ and astonishing 49.7\% $(n=99)$ females was less than 5000 rupees per month, income of 52\% males $(n=78)$ and $24.6 \%$ females (49) was between 5000-10000 rupees per month and income of only 4\% (n=6) males and $2.5 \%(n=5)$ females was above 15000 per month. The average dependent members in the house were 7 in number. Approximately $60.2 \%(n=210)$ patients had greater than 5 dependants. (Table 1$)$

Table 2: Gender based differences among some common observations related to DOTS

\begin{tabular}{|c|c|c|c|c|c|c|c|c|}
\hline \multirow[t]{2}{*}{ Variables } & \multirow[t]{2}{*}{ Classification } & \multicolumn{2}{|c|}{ Males } & \multicolumn{2}{|c|}{ Females } & \multicolumn{2}{|c|}{ Total } & \multirow[t]{2}{*}{$p$ value } \\
\hline & & $(\mathbf{n})^{*}$ & $(\%)^{\square}$ & (n) & $(\%)$ & (n) & $(\%)$ & \\
\hline \multirow{3}{*}{$\begin{array}{c}\text { Are you following } \\
\text { DOTS }\end{array}$} & Yes & 142 & 94.7 & 187 & 93.9 & 329 & 94.3 & \multirow{3}{*}{0.02} \\
\hline & No & 6 & 4.0 & 11 & 5.5 & 17 & 4.9 & \\
\hline & Don't know & 2 & 1.3 & 1 & 0.5 & 3 & 0.8 & \\
\hline \multirow{3}{*}{$\begin{array}{l}\text { DOTS is effective } \\
\text { against TB }\end{array}$} & Yes & 138 & 92.0 & 177 & 88.9 & 315 & 90.2 & \multirow{3}{*}{0.03} \\
\hline & No & 4 & 2.7 & 7 & 3.5 & 11 & 3.1 & \\
\hline & Don't know & 8 & 5.3 & 15 & 7.5 & 23 & 6.6 & \\
\hline \multirow[t]{2}{*}{ When to stop ATT } & When symptoms end & 19 & 12.7 & 28 & 14.1 & 47 & 13.5 & \multirow{2}{*}{$<0.01$} \\
\hline & When doctor advices & 131 & 87.3 & 171 & 85.9 & 302 & 86.5 & \\
\hline
\end{tabular}

$* \mathrm{n}=$ Frequency, $\quad \%=$ Percentage, $\neq p$ value $<0.05=$ significant, $<0.01=$ very significant, $<0.001=$ highly significant

The analysis shows that $94 \%(n=329)$ of the patients are following the DOT therapy strictly and regularly whereas 5\% are those who do not take medicine regularly and skip their medicines. Majority $(90.2 \%$, $\mathrm{n}=315$ ) believed that DOTS was an effective treatment against TB while 7\% were not sure of its effectiveness. Most of the patients $(86.5 \%, \mathrm{n}=302)$ knew that the treatment should only be stopped on the doctor's advice only where as $13.5 \%(n=47)$ believed that there is no need to continue the treatment as soon as the symptoms end. (Table 2)

Table 3: Reasons for discontinuing ATT

\begin{tabular}{|c|c|c|c|c|c|c|c|c|}
\hline Parameters Studied & Classification & \multicolumn{2}{|c|}{ Males } & \multicolumn{2}{|c|}{ Females } & \multicolumn{2}{|c|}{ Total } & \multicolumn{1}{c|}{$\boldsymbol{p}$ value } \\
\hline \multirow{2}{*}{ Multiple drugs before breakfast } & & $(\mathbf{n})^{*}$ & $(\boldsymbol{\%})$ & $\mathbf{( n )}$ & $\mathbf{( \% )}$ & $\mathbf{( n )}$ & $\mathbf{( \% )}$ & \\
\cline { 2 - 9 } & Yes & 129 & 86.0 & 190 & 95.5 & 319 & 91.4 & \multirow{2}{*}{$<0.01$} \\
\hline
\end{tabular}




\begin{tabular}{|c|c|c|c|c|c|c|c|c|}
\hline \multirow{2}{*}{ Long duration of the therapy } & Yes & 139 & 92.7 & 189 & 94.9 & 328 & 93.9 & \multirow{2}{*}{$<0.01$} \\
\cline { 2 - 9 } & No & 11 & 7.3 & 10 & 5.0 & 21 & 6.0 & \\
\hline \multirow{2}{*}{ Large doses to be taken orally } & Yes & 119 & 79.3 & 147 & 73.8 & 266 & 76.2 & \multirow{2}{*}{0.03} \\
\cline { 2 - 8 } & No & 31 & 20.7 & 52 & 26.1 & 83 & 23.8 & \\
\hline \multirow{2}{*}{ Side effects of the drugs } & Yes & 97 & 64.7 & 114 & 57.3 & 211 & 60.4 & \multirow{2}{*}{0.064} \\
\cline { 2 - 8 } & No & 53 & 35.3 & 85 & 42.7 & 138 & 39.5 & \\
\hline \multirow{2}{*}{$\begin{array}{c}\text { Use of drug during pregnancy and } \\
\text { lactation }\end{array}$} & Yes & 103 & 68.7 & 128 & 64.3 & 231 & 66.2 & \multirow{2}{*}{0.07} \\
\cline { 2 - 8 } & No & 47 & 31.3 & 71 & 35.7 & 118 & 33.8 & \\
\hline $\begin{array}{c}\text { Financial Burdens of treatment } \\
\text { (including distance and fares of } \\
\text { transportation) }\end{array}$ & Yes & 121 & 80.7 & 176 & 88.4 & 297 & 85.1 & \multirow{2}{*}{$<0.01$} \\
\cline { 2 - 8 } & No & 29 & 19.3 & 23 & 11.5 & 52 & 14.9 & \\
\hline $\begin{array}{c}\text { Family, community and household } \\
\text { influences }\end{array}$ & Yes & 117 & 78.0 & 161 & 80.9 & 278 & 79.6 & \multirow{2}{*}{0.02} \\
\cline { 2 - 7 } & No & 33 & 22.0 & 38 & 19.1 & 71 & 20.3 & \\
\hline
\end{tabular}

$* \mathrm{n}=$ Frequency, $\quad \%=$ Percentage, $\neq p$ value $<0.05=$ significant, $<0.01=$ very significant, $<0.001=$ highly significant

The patients were also asked about the reasons they considered for leaving the treatment for TB based on their experiences and believe. Approximately $91 \%(\mathrm{n}=319)$ patients regarded the number of tablets taken per dose as the reason for leaving the treatment. Majority of the patients agreed that long duration of the therapy $(93.9 \%, \mathrm{n}=328)$ and large doses taken orally $(76.2 \%, \mathrm{n}=266)$ are important reason for the non-compliance of patients with the anti-tuberculosis treatment. Side effects of the anti-TB drugs were experienced by $60.4 \%$ $(\mathrm{n}=211)$ of the patients. Among these patients, $58.3 \%(\mathrm{n}=123)$ developed orange colored body secretions, $6.2 \%$ $(n=13)$ developed joint pain especially in limbs, $4.2 \%(n=9)$ developed red green color blindness, $5.2 \%(n=11)$ have complained of hair fall and $10 \%(\mathrm{n}=21)$ developed jaundice. A considerable number of the patients $(33.8 \%, \mathrm{n}=118)$ believed that taking ATT during pregnancy will harm their child. They also feared that during lactation, the drugs can be secreted in breast milk that can have toxic effects on their child's health. Although, the drugs in DOTS are supplied free of cost to the patients but several other financial bur dens prevent the patients from continuing the treatment which is reflected from the data as well as $85.1 \%, n=297$ patients had financial problems including fares of the transport. Patients working on daily wages were affected most as they had to visit hospital daily to take medicines instead of going to work. A very important factor in non-compliance of ATT was social influence. Majority of the patients $(79.6 \%, n=278)$ believed that family, community and household influences have a major role in their decision to discontinue the medication for TB. They were afraid that they will be isolated and abandoned by their family members and other community members so they discontinue the medicine on their own as soon as the symptoms are reduced. (Table 3)

Table 4: Knowledge and Myths related to ATT

\begin{tabular}{|c|c|c|c|c|c|c|c|c|}
\hline \multirow[t]{2}{*}{$\begin{array}{c}\text { Parameters } \\
\text { Studied } \\
\end{array}$} & \multirow[t]{2}{*}{ Classification } & \multicolumn{2}{|c|}{ Males } & \multicolumn{2}{|c|}{ Females } & \multicolumn{2}{|c|}{ Total } & \multirow[t]{2}{*}{$p$ value } \\
\hline & & $(\mathbf{n})^{*}$ & $(\%)$ & (n) & $(\%)$ & (n) & $(\%)$ & \\
\hline \multirow{3}{*}{ Is TB curable? } & Yes & 132 & 88.0 & 180 & 90.4 & 312 & 89.4 & \multirow{3}{*}{0.01} \\
\hline & No & 3 & 2.0 & 3 & 1.5 & 6 & 1.7 & \\
\hline & Don’t know & 15 & 10.0 & 16 & 8.0 & 31 & 8.9 & \\
\hline \multirow{3}{*}{$\begin{array}{c}\text { Possible } \\
\text { recurrence of the } \\
\text { disease despite } \\
\text { treatment }\end{array}$} & Yes & 27 & 18.0 & 37 & 18.6 & 64 & 18.4 & \multirow{3}{*}{0.02} \\
\hline & No & 116 & 77.3 & 158 & 79.4 & 274 & 78.5 & \\
\hline & Don't know & 7 & 4.7 & 4 & 2.0 & 11 & 3.1 & \\
\hline \multirow{3}{*}{$\begin{array}{l}\text { Cure of TB in } \\
\text { other institutions }\end{array}$} & Homeopathic & 34 & 22.7 & 56 & 28.1 & 90 & 25.8 & \multirow{3}{*}{0.36} \\
\hline & Eastern Medicine & 83 & 55.4 & 73 & 36.7 & 156 & 44.7 & \\
\hline & Spiritual Modalities & 33 & 22.0 & 70 & 35.1 & 103 & 29.5 & \\
\hline \multirow{3}{*}{$\begin{array}{l}\text { ATT causes } \\
\text { infertility }\end{array}$} & Yes & 29 & 19.3 & 52 & 26.1 & 81 & 23.2 & \multirow{3}{*}{0.12} \\
\hline & No & 88 & 58.7 & 99 & 49.7 & 187 & 53.6 & \\
\hline & Don't know & 33 & 22.0 & 48 & 24.1 & 81 & 23.2 & \\
\hline
\end{tabular}

"n = Frequency, $\%=$ Percentage, $\neq p$ value $<0.05=$ significant, $<0.01=$ very significant, $<0.001=$ highly significant

Patients were evaluated about the myths related to TB and on being asked whether TB is curable or not, $89.4 \%(\mathrm{n}=312)$ patients believed that TB is a curable disease. Most of the patients $(78.5 \%, \mathrm{n}=274)$ believed that there is a possibility of recurrence of the disease despite treatment. The patients also believed that the cure of TB 
is present in other institutions. Approximately $45 \%(\mathrm{n}=156)$ patients had belief that eastern medicine can cure TB while $25.8 \%(\mathrm{n}=90)$ and $29.5 \%(\mathrm{n}=103)$ patients thought that homeopathic and spiritual modalities respectively were favorable as far as the treatment of TB is concerned. On enquiring whether infertility is a complication of ATT, $23.2 \%(n=81)$ patients agreed while similar number of patients were not sure if ATT causes infertility or not. (Table 4)

\section{Discussion:}

TB is a major contributor of the burden of disease in developing countries. It has received considerable attention in recent years but poor adherence to the treatment and phobia for the ATT drugs is still a common problem. Although analysis reveals that in patient's view DOT is effective against TB and patient follow it regularly but the chain of factors and phobias identified in this research are intricately linked and likely to have a combined effect on patient's adherence to treatment. There is a need for a shift in perspective to give great attention to these factors and phobias in relation to TB infection.

Another important issue explored in this research includes how gender determines response to treatment. Females in Pakistan, rely on their husbands and other males in the family for social and financial support, they have limited freedom to travel. This can be the main reason in non-adherence to medication in females. Phobia in female patients regarding ATT in pregnancy and lactation is also an important factor which was not studied in this study.

Community, family members, colleagues indirectly influence medication. Patient under strong influence of stigma among family member and phobia of isolation from community hide their disease. Employees hide their disease state because of the fear of unemployment. Patients' perception of marriage prospects greatly influences the treatment as well.

There are certain side effects of drugs used in the treatment of TB and they are mentioned in a number of studies. Orange-yellow coloration of urine, tear and other body fluids, neuropathy, jaundice, red-green color blindness, all these can influence the decision of the patients to abandon treatment. Complete information of drug side effects should be provided to patients before they experience it.

New drug regimen should be introduced to decrease the long duration of treatment. ${ }^{[18,19]}$ Phobia for the drug therapy can be reduced if the patients understand the importance of completing treatment and consequences of defaulting. Race and gender are important social factors that play a very important role in the continuation or completion of the therapy. Cultural beliefs and use of traditional medicines can also cause hindrance in patients' compliance. Use of other means of treatment e.g. Hakim and homeopathic medicine should be discouraged.

\section{Conclusion:}

This research indicates that patients during TB medication experience significant challenges. The fact that these patients are not counseled adequately regarding the treatment options and side effects of the drugs makes it difficult for the patient to adhere to the treatment. Poverty is another challenge that compromises the adherence to treatment. There is a stigma associated with the disease which makes life further difficult for the patient. All of these issues need to be addressed in order to achieve the success in treating the TB patients. New interventions to promote treatment adherence and eliminate phobia could be designed while keeping these factors in mind. Further research is needed both to understand people's experience of TB and its treatment and to develop approaches to improve them.

\section{References:}

[1] Aguwa N (2004), Tuberculosis in therapeutics basic of clinical pharmacy in the tropics, 3rd (ed), pp. $201-204$.

[2] R. Beaglehole, R. Bonita, and T. Kjellstrom, (1997). Basic Epidemiology (WHO: Geneva).

[3] Dye, C. (2006) Global epidemiology of tuberculosis. Lancet; 367: 938-939.

[4] Zumla, A., Malon, P. \& Henderson, J. (2001). Impact of HIV infection on tuberculosis. JAMA;4:33-40.

[5] World Health Organization (1996). Group at risk. WHO's report on the tuberculosis epidemics. The World Health Organization, Geneva, pp.42-55.

[6] Corbett, E. L., Marston, B., Churchyard G. J. \& De Cock, K. M. (2006). Tuberculosis in sub-Saharan Africa: opportunities, challenges and change in the era of antiretroviral treatment. Lancet; 367: 926-37.

[7] Kassu A., Mengistu G., Ayele B., et al (2007). Coinfection and Clinical Manifestations of Tuberculosis in Human Immunodeficiency Virus-Infected and Unifected adults at a Teaching Hospital, Northwest Ethiopia. J. Microbiol. Immunol. Infect, 40: 116-122.

[8] Munro, S. A., Lewin, S. A., Smith, H. J., Engel, M. E., Fretheim, A., Volminket, J. (2007). Patient Adherence to Tuberculosis Treatment: A Systematic Review of Qualitative Research. PLoS Med; 4(7): e238.

[9] Khan MA, Walley JD, Witter SN, Shah SK, Javeed S (2005) Tuberculosis patient adherence to direct observation: Results of a social study in Pakistan. Health Policy Plan 20: 354-365

[10] Khan A, Walley J, Newell J, Imdad N (2000) Tuberculosis in Pakistan: Socio-cultural constraints and opportunities in treatment. Soc Sci Med 50: 247-254

[11] Jaiswal A, Singh V, Ogden JA, Porter JDH, Sharma PP, et al. (2003) Adherence to tuberculosis treatment: Lessons from the urban setting of Delhi, India. Trop Med Int Health 8: 625-633 
[12] Salla A.Munro,Simon A.Lewin,Helen J.Smith,Mark E.engel,Jimmy Volmink Patients Adherence to tuberculosis treatment: A systematic review of qualitative research

[13] Edginton ME, Sekatane CS, Goldstein SJ (2002) Patients' beliefs: Do they affect tuberculosis control? A study in a rural district of South Africa. Int J Tuberc Lung Dis 6: 1075-1082

[14] Nair D, George A, Chacko K (1997) Tuberculosis in Bombay: New insights from poor urban patients. Health Policy Plan 12: 77-85

[15] Johansson E, Winkvist A (2002) Trust and transparency in human encounters in tuberculosis control: Lessons learned from Vietnam. Qual Health Res 12: 473-491

[16] Johansson E, Diwan VK, Huong ND, Ahlberg BM (1996) Staff and patient attitudes to tuberculosis and compliance with treatment and exploratory study in a district in Vietnam. Tuber Lung Dis 77: 178-183

[17] Greene JA (2004) An ethnography of non-adherence: Culture, poverty, and tuberculosis in urban Bolivia. Cult Med Psychiatry 28 : $401-425$.

[18] Liefooghe R, Michiels N, Habib S, Moran MB, de Muynck A (1995) Perception and social consequences of tuberculosis: A focus group study of tuberculosis patients in Sialkot, Pakistan. Soc Sci Med 41: 1685-1692

[19] Watkins RE, Rouse CR, Plant AJ (2004) Tuberculosis treatment delivery in Bali: A qualitative study of clinic staff perceptions. Int J Tuberc Lung Dis 8: 218-225

[20] Mata JI (1985) Integrating the client perspective in planning a tuberculosis education and treatment program in Honduras. Med Anthropol 9: 57-64

[21] Coleman RL, Wilkinson D, MacAdam KP (1998) Voluntary lay supervisors of directly observed therapy for tuberculosis in Africa. Trop Doc 28: 78-80

[22] Edginton ME, Sekatane CS, Goldstein SJ (2002) Patients' beliefs: Do they affect tuberculosis control? A study in a rural district of South Africa. Int J Tuberc Lung Dis 6: 1075-1082. 